\section{Design and Construction of an Inexpensive Plexiglas Chilling Chamber to Study Flowering in Olives}

\author{
Nasir S.A. Malik and Joe M. Bradford
}

U.S. Department of Agriculture, Agricultural Research Service, Kika de la Garza Subtropical Agricultural Research Center, 2413 East Business Highway 83, Weslaco, TX 78596

\section{Additional index words. flowering, chilling}

Flowering in olives (Olea europaea L.) requires a night-time regime of chilling ( 2 to 7 ${ }^{\circ} \mathrm{C}$ ) and relatively warm daytime temperatures (12.5 to $\left.23.5^{\circ} \mathrm{C}\right)$ (Hartman and Whisler, 1975). Such temperatures are uncommon in southern Texas where olives growth is mostly vegetative (Denney and McEachern, 1983). There is, however, a strong interest among producers in southern Texas to develop appropriate cultivars, or formulate other chemical or physical strategies that would facilitate flowering and fruiting in olives under various weather conditions of southern Texas. To study flowering in olives, plant growth chambers capable of producing chilling temperatures $\left(2\right.$ to $\left.7{ }^{\circ} \mathrm{C}\right)$ are required. Commercial growth chambers for this purpose, however, are generally quite expensive, approaching $\$ 50,000$ to $\$ 70,000$ for growing small trees. In addition, most commercial growth chambers do not maintain temperatures $<4^{\circ} \mathrm{C}$, and even at that temperature an hourly increase of 2 to $3{ }^{\circ} \mathrm{C}$ for defrosting occurs automatically (Conviron, 2001).

Therefore, we have designed and constructed simple and inexpensive environmental chamber (about \$ 5000) that can reproducibly induce flowering in olives. The advantage of growing plants in this type of chamber, in addition to cost benefits, is that the plants can be grown under natural light, thus minimizing variations in plant growth that may occur under strictly artificial light. In addition, it allows gradual increase and decrease in temperatures at the beginning and end of the day.
Fig. 1. Schematic diagram showing an exploded view of the environmental chamber (A), with details on the layout of Plexiglas wall assembly (B), joints at the corner of walls (C), wooden base-walls layered with insulation sheets (D), and the irrigation system $(\mathbf{E})$.

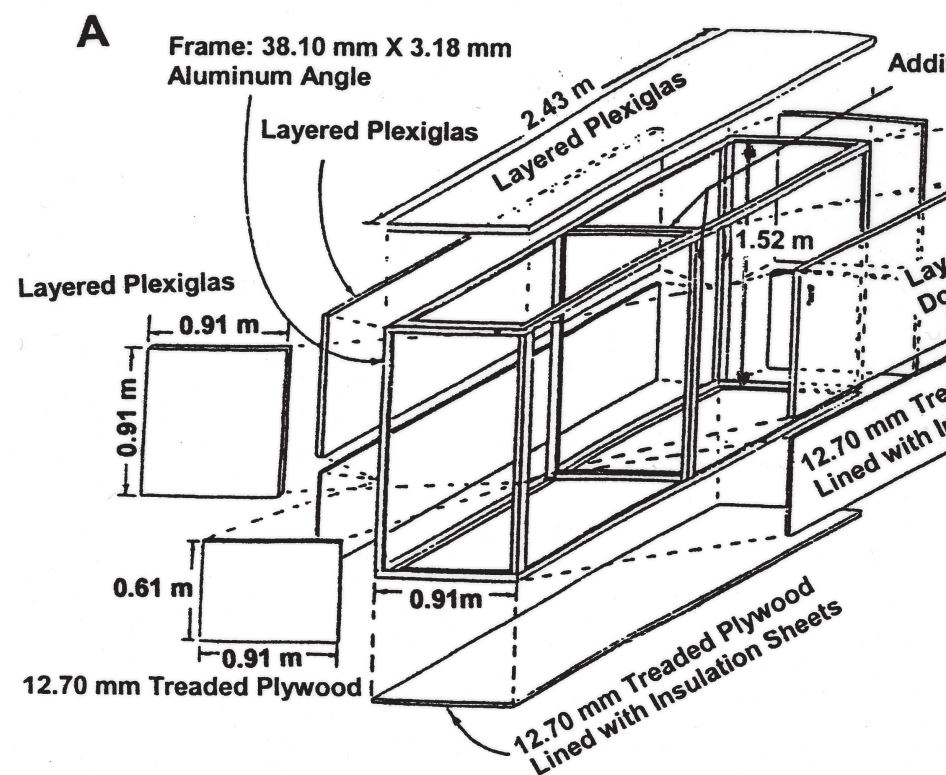

ASSEMBLY OF CHAMBER WALLS, BASE, TOP, AND FRAME

B

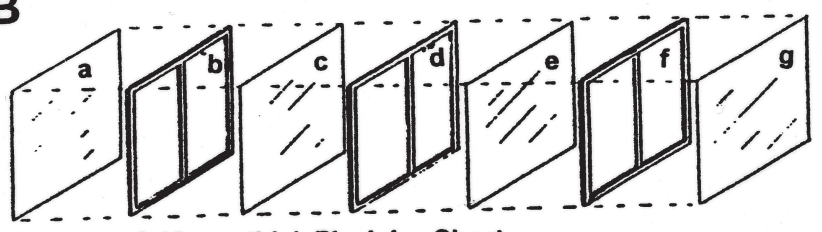

a, $c, e, \mathrm{~g}: 3.18 \mathrm{~mm}$ thick Plexiglas Sheet

b, $f: 6.35 \mathrm{~mm}$ thick $X 25.40 \mathrm{~mm}$ wide Plexiglas Spacer Frame

d : $12.70 \mathrm{~mm}$ thick $X \mathbf{2 5 . 4 0} \mathrm{mm}$ wide Plexiglas Spacer Frame
C

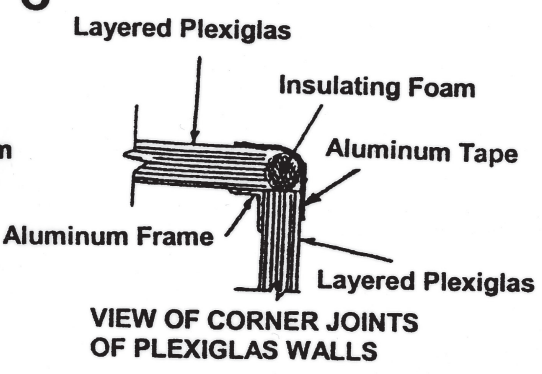

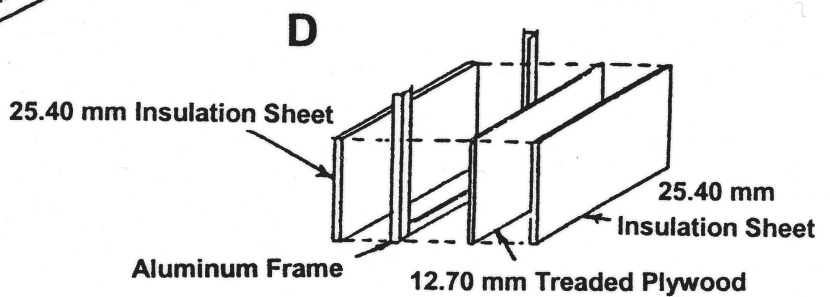

ASSEMBLY OF WOODEN BASE-WALLS

E

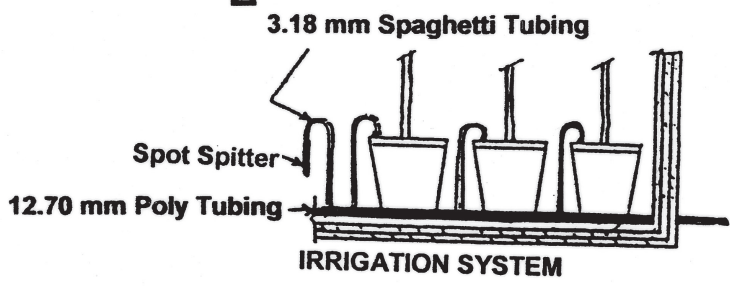

ASSEMBLY OF PLEXIGLAS WALLS AND DOORS 
Fig. 2. Front and back view of the environmental chamber with attachments.

The chamber's aluminum frame, Plexiglas walls, wooden base walls, doors, condenser, evaporator, and other components are shown in Figs. 1 and 2.

\section{Literature Cited}

Conviron. 2001. Product manual. Conviron, Winnipeg, Manitoba, Canada.

Denney,J.O. and G.R. McEachern. 1983. An analysis of several climatic temperature variables dealing with olive reproduction. J. Amer. Soc. Hort. Sci. 108:578-581.

Hartmann , H.T. and J.E. Whisler. 1975. Flower production in olives as influenced by various chilling temperature regimes. J.Amer. Soc. Hort. Sci. 100:670-674.

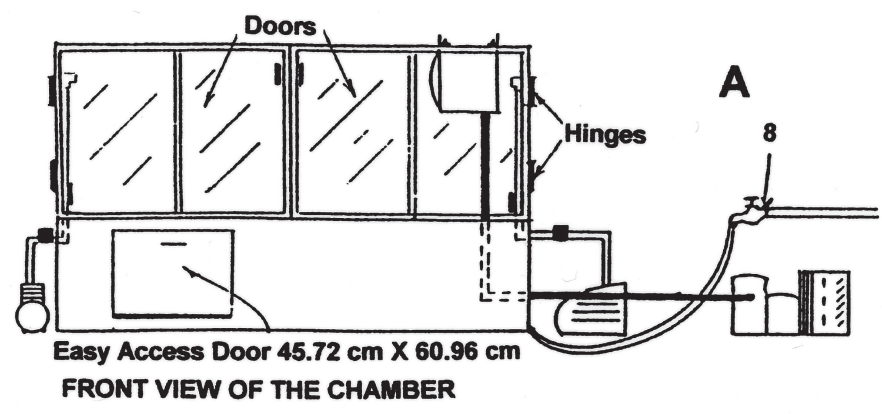

1. Compressor for Cooling Unit

2. Air Compressor

3. Electric Valves

4. Evaporator

5. Temperature Control Unit

6. Vacuum Pump

7. Temperature Recorder

8. Irrigation Water Supply
B

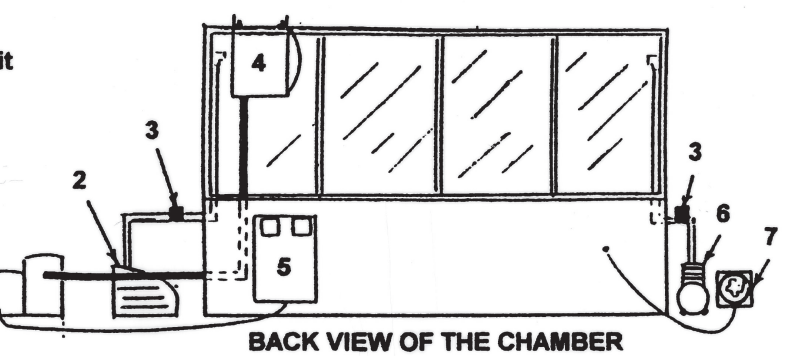

